\title{
IoT Technologies for Tackling COVID-19 in Malaysia and Worldwide: Challenges, Recommendations, and Proposed Framework
}

\author{
Ali Saadon Al-Ogaili ${ }^{1, *}$, Ameer Alhasan ${ }^{2}$, Agileswari Ramasamy ${ }^{1}$, Marayati Binti Marsadek ${ }^{1}$, Tengku \\ Juhana Tengku Hashim ${ }^{1}$, Ammar Al-Sharaa ${ }^{3}$, Mastura Binti Aadam ${ }^{3}$ and Lukman Audah ${ }^{2}$ \\ ${ }^{1}$ Institute of Power Engineering (IPE), Universiti Tenaga Nasional, Selangor, 43000, Malaysia \\ ${ }^{2}$ Faculty of Electrical and Electronic Engineering, Universiti Tun Hussein Onn Malaysia, Johor, 86400, Malaysia \\ ${ }^{3}$ Faculty of Built Environment, University of Malaya, Kuala Lumpur, 50603, Malaysia \\ *Corresponding Author: Ali Saadon Al-Ogaili. Email: Ali.Saadon@uniten.edu.my \\ Received: 06 August 2020; Accepted: 12 September 2020
}

\begin{abstract}
The Coronavirus (COVID-19) pandemic is considered as a global public health challenge. To contain this pandemic, different measures are being taken globally. The Internet of Things (IoT) has been represented as one of the most important schemes that has been considered to fight the spread of COVID-19 in the world, practically Malaysia. In fact, there are many sectors in Malaysia would be transformed into smart services by using IoT technologies, particularly energy, transportation, healthcare sectors. This manuscript presents a comprehensive review of the IoT technologies that are being used currently in Malaysia to accelerate the measures against COVID-19. These IoT technologies including smart thermal detection, surveillance network, and healthcare delivery technologies. In addition, the most potential IoT technologies developed by other nations to tackle COVID-19 are reviewed, including tracking and tracing systems based on IoT, adoption of IoT technologies in hospitals, and self-monitoring devices based on IoT. For these technologies to be incorporated in Malaysia, the main challenges with possible recommendations are discussed in this manuscript. Finally, this work proposes a conceptual framework to accelerate the battle pace with spread of COVID-19 in Malaysia by integrating IoT technologies used in fighting the outbreak of COVID-19 globally.
\end{abstract}

Keywords: Coronavirus; Internet of Things; healthcare; urban health system

\section{Introduction}

Coronavirus (COVID-19) outbreak was first detected in late December of 2019 in Wuhan-China and was declared as a global pandemic by the World Health Organization (WHO) in March 2020. To tackle this pandemic outbreak, decision-makers and national authorities in some countries presented a largescale preventive and proactive measures such as, rapid identification of cases initiatives, contact tracing, and enforcing social distancing measures through imposing nation-wide lockdowns. These measures took place to help in processes such as diagnosis, confirmed cases management, clustering and isolation of confirmed cases, and estimating numbers of potential new cases [1-3]. Malaysia has introduced a set of

This work is licensed under a Creative Commons Attribution 4.0 International License, which permits unrestricted use, distribution, and reproduction in any medium, provided the original work is properly cited. 
health measures aimed at mitigating the spread of COVID-19. In this context, the Internet of Things (IoT) was notably one of the technologies that demonstrated its significance and potential in the process of restraining the spread of this viral infection in the country. IoT has the potential to be a powerful tool to manage the COVID-19 pandemic, due to its scalability potential and the automated nature of its solutions. The presence of IoT technology has shown exponential growth in multiple industries and sectors such as automotive manufacturing and the healthcare sector [4,5].

There are four main functional components of IoT namely, data collection, data transfer, data analytics, and data storage. Data collection can be conducted through the use of installed sensors on end-user mobile hardware such as, phones, robots, and health monitors. Transferring the collected data to a central cloud server to perform data analytics and decision-making, for instance, if machine maintenance is required to prevent unforeseen future malfunction or, a patient checkup is required [6-8]. The implementation of IoT systems in the medical field manifested itself in the form of various mechanisms like, smart sensors, medical equipment, big data, cloud computing, telemedicine, clinical information system, and various other types of applications. In order to battle COVID-19, the implementation of IoT technologies in the healthcare sector can be applied for different purposes according to their usage, such as remote patient monitoring, remote tracking of the contact network and hand wash monitoring sensor-based devices $[9,10]$.

Numerous and diverse collected datasets through various data collection techniques meant that further integrating IoT applications in the healthcare sector especially during the COVID-19 pandemic is promising a faster, more accurate response and a better healthcare service overall. IoT has the potential to be used in the process of tracing the origin of an outbreak contact network. A promising recent study conducted by a research group from Massachusetts Institute of Technology (MIT), collected data from mobile phones to trace the spread of dengue virus during 2013 and 2014 in Singapore. The study illustrated that mapping IoT mobile data from infected patients using geographic information system (GIS) have the potential to help epidemiologists in, locating patient zero and help to identify all the contacts with infected patients, for further examination [11]. A worldwide map that outlined the current IoT technologies used for handling and controlling COVID-19 outbreak is illustrated in Fig. 1.

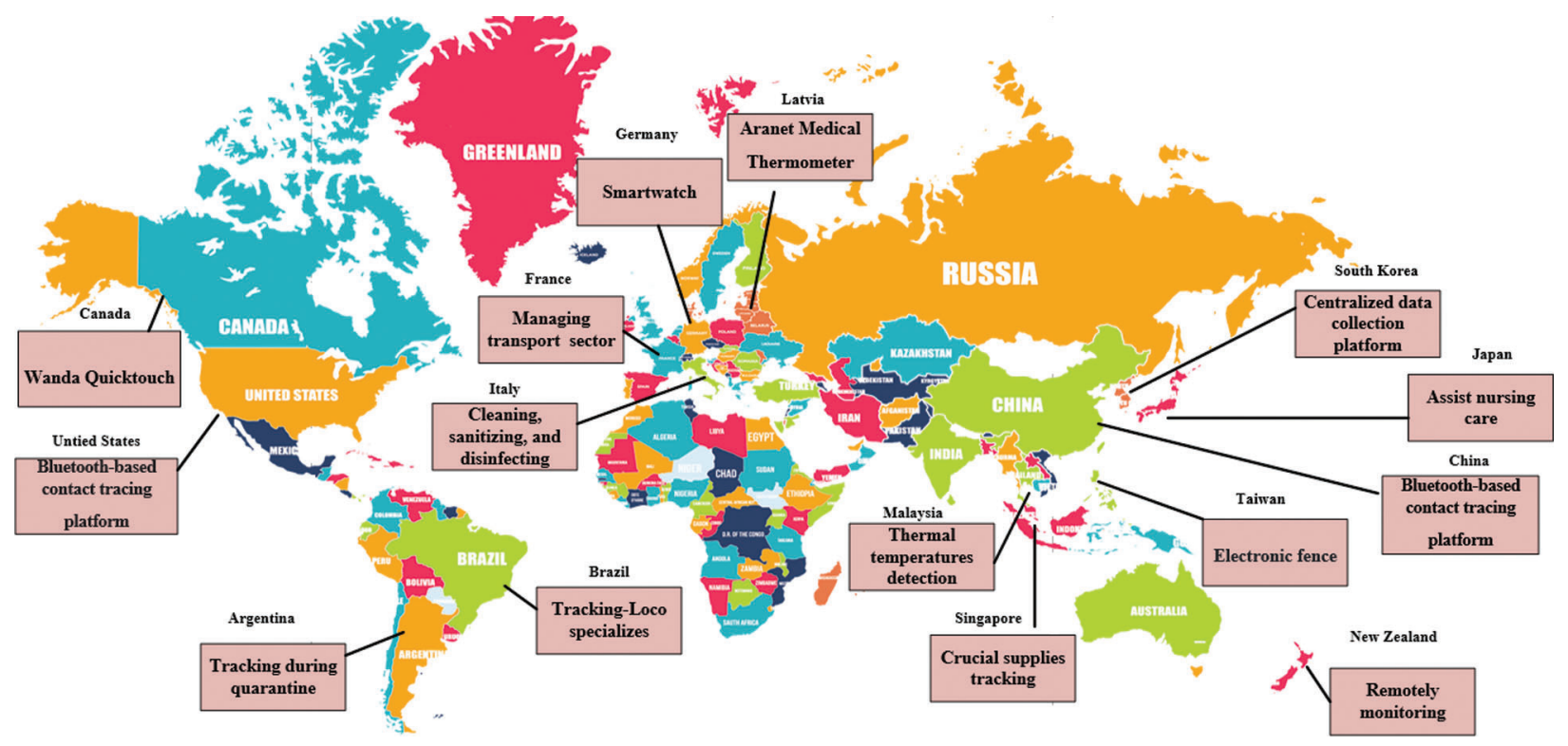

Figure 1: A worldwide map of IoT technologies used for fighting COVID-19 pandemic 
Recently, few researchers have comprehensively reviewed the adoption of IoT technologies in response to the spread of COVID-19 pandemic. For example, the authors in [12] presented the potential roles that IoT technologies can perform for mitigating the outbreak of COVID-19 contagion. Similarly, in [13], the researchers outlined the major facets correlated to the spread of COVID-19 pandemic, among which emerging technologies, such as IoT applications, employed to mitigate the impact of Covid-19 Pandemic. However, their works have not emphasized on facilitating an adaptation scheme to a particular country. In addition, in their research initiatives have not highlighted the challenges associated with implementing the IoT technologies in a particular region.

This manuscript fills up the aforementioned gap by critically reviewing prominent IoT applications globally used to curb COVID-19 pandemic, which emphasizes on their potential emergence alongside the current IoT technologies in Malaysia. Moreover, this review identifies the main challenges and issues arising with the incorporation of IoT technologies to tackle COVID-19 pandemic in Malaysia. Furthermore, this article proposes a generic framework that provides a generic integration between globally implemented IoT technologies and the executed IoT technologies in Malaysia for fighting COVID-19 pandemic.

This article follows a methodological framework, whereby two sets of keywords were selected to search for available articles according to the region where the IoT technology adaptation took place to curb the spread of the pathogen. The first set of keywords were (Coronavirus or COVID-19 and; Internet of Things, or IoT and; Malaysian healthcare and; adoption or adaptation or integration) chosen to investigate the IoT technologies in Malaysia. The second set of keywords were (Coronavirus or COVID-19 and; Internet of Things, or IoT and adoption or adaptation or integration) chosen to investigate how other nations around the globe have employed IoT technology complemented with news articles highlighted the usage of these technologies to fight the pathogen's outbreak. Two stages of screening took place to assess articles relevance in each keyword sets. In the first stage, articles' titles and abstracts were screened followed by a full article examination and a comprehensive content analysis of the relevant articles. The inclusion criteria were as the following; journal articles, conference papers/proceedings and, books paired with a selected news articles from reputable sources, and a set of other published documents by health authorities globally, all the resources gathered were published in English. this study utilizes two databases (Scopus and, Web of Science) and google scholar search engine to track the published papers that fits the scope of this article. The findings of the former databases/search engines were paired with a set of selected news articles/published documents from reputable sources to complement the found research articles with the most up to date news about the spread of COVID-19 and the applications of IoT technologies to battle it, as shown in Fig. 2.

The main contributions of this review are as follows:

This paper addresses the IoT technologies to tackle COVID-19 outbreak in Malaysia and worldwide.

The outline of this review will help the countries to decide on an appropriate IoT technology to tackle COVID-19 outbreak and identify its technical aspects.

The review raises many challenges and issues associated with the integration of IoT technologies in fighting COVID-19 pandemic with possible recommendations.

This study proposes a generic framework that delivers a generic adoption between globally implemented IoT technologies and the executed IoT technologies in Malaysia for tackling COVID-19 outbreak.

This paper is structured as per the following: Section 2 presents a background on IoT technologies in Malaysia, where these technologies are enabled to collect the data in various applications to change the way in which sectors are implemented. Moreover, a brief description of the main IoT technologies of health measures to mitigate the spread of the COVID-19 in Malaysia is presented in Section 3. In 


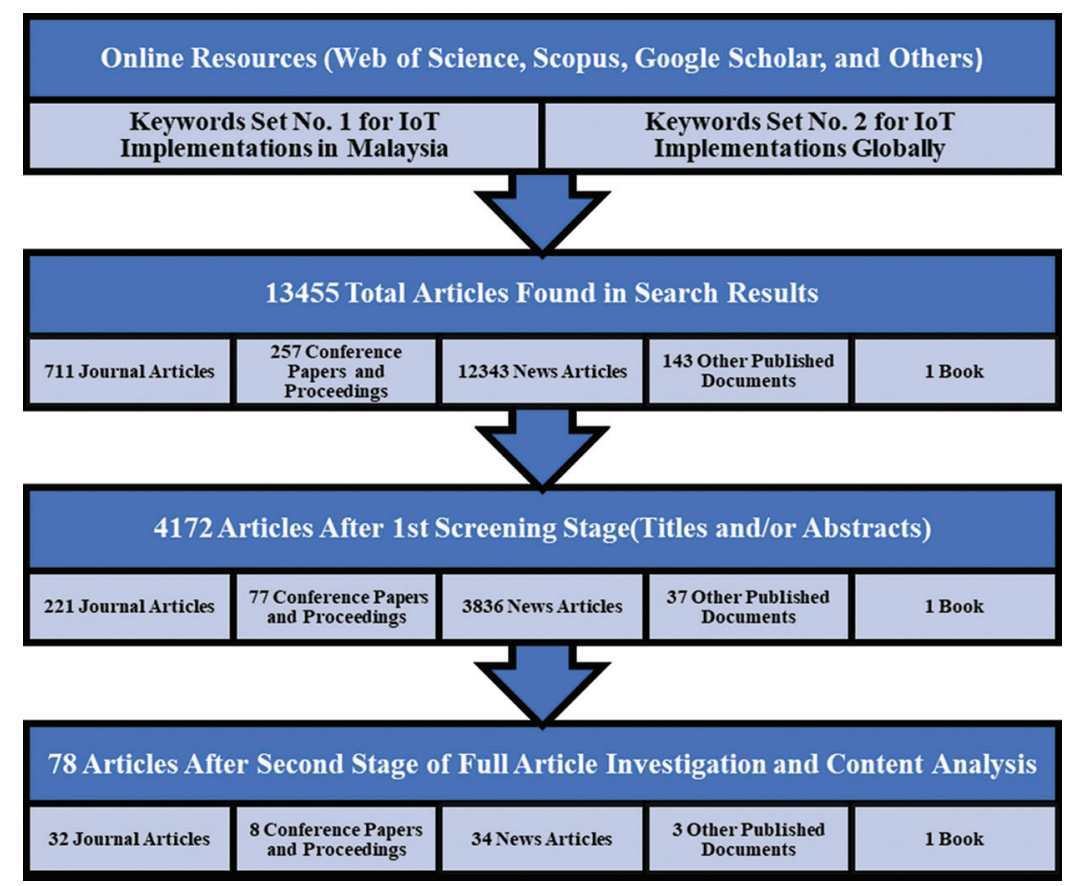

Figure 2: The paper's methodological framework

addition, the most important IoT technologies that have been applied in other countries are introduced in Section 4 According to the status of these technologies to be applied in Malaysia, the major challenges are analyzed in Section 5. The impact of IoT applications on mitigating the spread of COVID-19 pandemic is outlined in Section 6. The limitations of the study are highlighted in Section 8. Proposed IoT integration framework to cope with pathogen spread is outlined in Section 7. The main recommendations and conclusions are presented in Section 9.

\section{Overview of IoT Technologies in Malaysia}

To drive IoT adoption in Malaysia, the Malaysian Ministry of Science launched the national IoT strategic roadmap, which is expected to fund about US $\$ 2.49$ billion by 2020 [14]. In this respect, the data would be collated from both inanimate and living things by using sensors integrated to the internet via wireless communication system [15]. In addition, Greater Kuala Lumpur (KL) project has been planned with the ambition of transforming the metropolis into a smart city based on IoT technologies [16]. As illustrated in Fig. 3, many sectors would be transformed into smart services by using IoT technologies, particularly energy, transportation, healthcare sectors.

The roadmap strategy of energy sector based on IoT in Malaysia is outlined in 2009, where the implementation of smart grids and smart meters has been adapted in three zones, namely Bayan Lepas in the north, Bukit Bintang in the central region and Medini in the southern part of the Peninsula [17,18]. As a result, the plan of developing smart grid and smart metering was actually driven mainly by three factors, namely aging legacy infrastructure, financial, and environmental crisis.

Since the introduction of smart cities initiatives as part of the 11th Malaysia Plan (2016-2020), Malaysia has started deploying an intelligent IoT network in cities like Kuala Lumpur, Johor, Selangor, and Putrajaya [19]. These projects incorporated IoT, cloud computing, big data analytics and spatial geographic information integration in their smart city planning. With smart mobility being a key aspect of its smart 


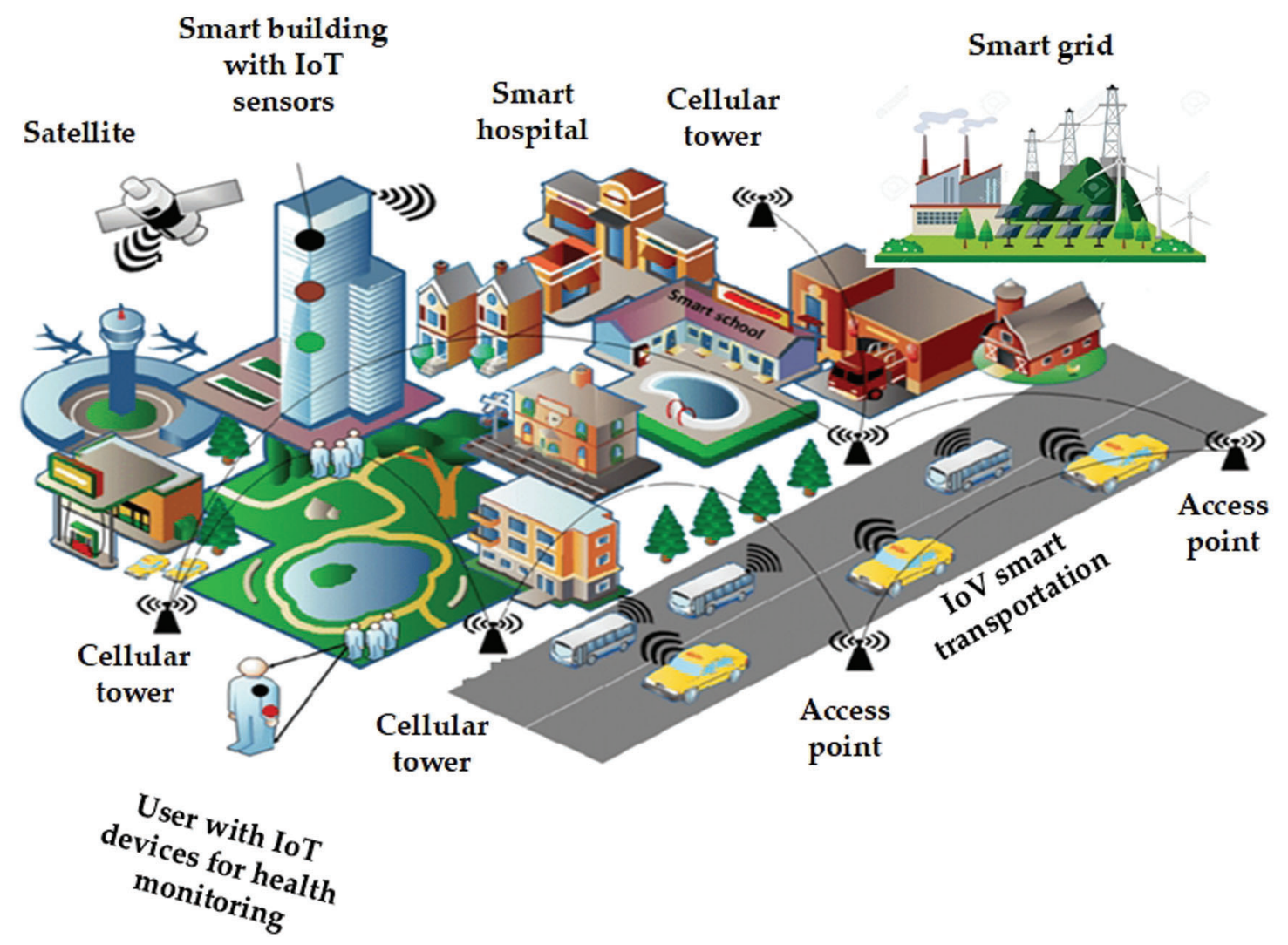

Figure 3: Scheme diagram of Great KL smart city based IoT technologies

cities vision, Malaysia launched its intelligent transport system blueprint (2017-2022) to upgrade its current transportation system, with big data analytics forming the core of the system. Data gathered from information and communications technology (ICT) infrastructure is analyzed to gain insights and provide alternative choices for efficient operations. Also, Malaysia also seeks the chance to enhance trade facilities and enhance Malaysia's competitive advantage regarding supply chain management practices. Suggested applications include E-parking, taxi reservations, bus transportation information, and finally yet importantly travel and train information tips with real-time information for easy traveling $[14,19]$.

By establishing the policies, strategies and initiatives in Malaysia, enhancing the quality of healthcare services can be achieved through smart healthcare technologies [20]. In this respect, the adoption of smart healthcare devices would be applied for many purposes such as patient monitoring to help managing particular chronic conditions, recovering from injuries, and mobile health which uses a new concept of using smart mobile devices to create efficient healthcare services and solutions [21]. This in line with Malaysia's goals in the healthcare sector, which are to promote healthy living and wellness assisted by digital lifestyle services through enhanced health service availability everywhere and anytime.

\section{Current IoT Implementations in Malaysia for Curbing COVID-19}

The application of IoT in the field of healthcare services is commonly named medical IoT (MIoT). MIoT goal is to establish the decision-making centered models for analyzing big data. MIoT can be exploited to prevent and control the spread of COVID-19 when backed up by information technology (IT) especially from the electronics and telecommunication fields, geared towards human biology, and medicine [22,23]. 
The following will list down, and review prominently used IoT technologies based on their potential usage in fighting COVID-19 in Malaysia.

\subsection{Smart Thermal Detection}

\subsubsection{The Technical Aspects of Smart Thermal Detection}

This IoT technology relies on thermal cameras which are sensitive to the radiations within the Infra-Red (IR) section of the electromagnetic spectrum, without sensing visible light. This property makes it insensitive to visible light in ambient illumination conditions such as, intensity, saturation, or direction of light [24].

There do exist a variety of digital cameras nowadays, some of which are equipped with different detection properties outside the visible RGB color spectrum. Thermal cameras are one type which operates in the IR thermal wavelengths between $(8-14 \mu \mathrm{m})$. The band which these cameras are detecting is normally referred to as thermal IR emission. Through associating thermal IR radiation emissions strength of object to its temperature [25], which can be displayed on a monitoring screen or be linked to an automatic alarm system when registering temperatures higher than the threshold, this technology provides a smart mean of detection to cases of fever in passing human bodies. Thermal camera contains a lens made from germanium which images the IR radiation emitted out of the scene's objects or features within its detectable zone to a thermal sensor which is referred to as infrared focal plane array. Thermal imaging sensors are made in a way whereby pixels are tiny thermal IR emissions detecting devices constructed out of materials that are sensitive to thermal IR radiation [25]. This technique enables thermal cameras to discern the way thermal radiations are distributed in the scenes of which it is imaging as thermal images.

It is worth noting that there is another type of thermal imaging system that employs a temperature calibration process using a device called a black body. These imaging systems incorporate dual sensor configurations, of which one is a visual sensor and, the second is a thermal sensor both constructed within the camera. This configuration enables for a high degree of imaging accuracy, due to the black body calibration and the ability to provide continuous calibration. These systems can afford more flexibility and are potentially able to offer integration compatibility with numerous video management systems (VMSs) as well as access control devices.

\subsubsection{Applications of Smart Thermal Detection in Malaysia}

Countries implementing strong protective measures, such as tracking and contact tracing using IoT technologies, have shown that it is possible to reduce the spreading of COVID-19. With the WHO recommending temperature screening at the workplace, one of the measures implemented in Malaysia is the use of non-contact infrared thermometers to detect cases of high body temperature as an overlapping symptom with COVID-19 at all workplaces [26]. This measure is seen as critical in maintaining operations at essential businesses' sites such as factories, some residential buildings, and businesses and facilities of essential nature.

The Hong Kong-based company HKBN JOS is implementing a Smart IoT Thermal Detection Solution (SITD Solution) [27]. It is a cost-efficient and a timely service that applies a combination of a sophisticated IoT and an Artificial Intelligence (AI) temperature gauging technique to detect any fluctuations in registered body temperature and help recognize suspected viral infections before the site or office entry. The convenience of a body temperature tracking solution that does not require a human proximity to provide readings that enables real-time observation and alarm system, whereby the recorded data will be uploaded through a Wi-Fi or $4 \mathrm{G}$ mobile network, without the need for manual examination of body temperature is attractive. This system allows temperature monitoring without having the risk of being in proximity with whom may be infected [27,28]. The key features of SITD can be summed up as per the following: 
Scanning temperatures with an effective range of 1-3 m with a maximum scanning capacity of 20 people at an instance.

Real-time mobile application based alert notifications and data storage for 30 days if contact tracing is necessary.

Automatized process, whereby the system's automated workflow will report and notify fluctuations in visitor's temperature for medical staff to take action if necessary.

The Kuala Lumpur based Telekom Malaysia Berhad (TM) through its Research \& Development division (TM R\&D) has presented an IoT based smart technology to help in early detection of thermal abnormalities. Early Warning, Alert \& Response, or "EWAR" is TM's R\&D division latest approach that potentially enables measuring people's body temperature in public areas [29]. Body temperature examination is considered a necessary physiological indicator, it is also considered as an important symptom in the diagnosis of many previous influenza-like epidemics, which offers beneficial medical diagnostic information. The project development of EWAR started in the middle of February 2020 and it was developed on the division's Open Innovation Platform (OIP), which is Malaysia's first Open-source Software Development Digital Platform. OIP provided a durable digital infrastructure that helped to provide a comprehensive eco-system for effective service development [29,30]. The prominent features of EWAR solution can be summed up as per the following:

It is equipped with a dual-camera setup (thermal and optical) to enable detection of subjects' temperature abnormalities of approximately 15 individuals per second.

Real-time notification to the relevant authorities for emergency response when individuals with high fever are detected.

The ability to communicate with the national response team for COVID-19 in cases where early containment is needed.

\subsection{Surveillance Network}

\subsubsection{The Technical Aspects of Surveillance Network}

IoT technology enabled the usage of remote monitoring stations to monitor extremely hazardous and remote settings. Flying IoT based Unmanned Aerial Vehicles (UAVs) represents an example of video surveillance collected by drones which can be used to identify any suspicious activities among the crowds. Flying above the areas in question, while streaming recorded data via an onboard integrated transmission device using high-speed networks connectivity to a cloud-based server for analysis [31].

Drones in Video Surveillance Applications:

Recognizing crowd's abnormal behaviours.

Monitoring hazards of natural disasters such as, forest fires, rivers flooding or volcanic activities.

Facial recognition of people with criminal records and following targets if required.

Due to their operational nature drones requires an onboard high-speed wireless communication system. Broadband technologies like LTE and 5G with Low latency properties can improve speed and, precision of drowns response times. They have the ability for high speed communication and data transmission to a local computing system such as Multi-Access Edge Computing (MEC).

\subsubsection{Surveillance Network Applications in Malaysia}

Drones equipped with cameras and loudspeakers are considered an important tool in the fight against the spread of the COVID1-9 disease [32]. Loudspeakers are serving as an auditory communication device whereby individuals can be warned against mass gatherings and roaming contaminated zones. The 
Malaysian police forces have utilized drones to perform surveillance and monitoring missions over seven villages in Sungai Lui, Hulu Langat, Selangor during the Enhanced Movement Control Order (EMCO) [33]. The safety aspect of having a radio-controlled (RC) drones enabled law enforcement to monitor locations in their respective jurisdiction areas to ensure the application of preventive measures without having to risk physical contact. Collected data can be examined and reviewed by relevant authorities such as the Department of Social Welfare and the Malaysian Ministry of Health (MoH) [33,34]. An important advantage of using drones is the operation capability without the need for human interaction which may endanger human lives by increasing the chances of cross-infection. The introduction of a surveillance layout that introduces multiple security, safety, and privacy solutions by incorporating a mobile IoT technology can contribute to the betterment of service provision to a variety of relevant potential users using a suite of distributed systems, shown in Fig. 4.

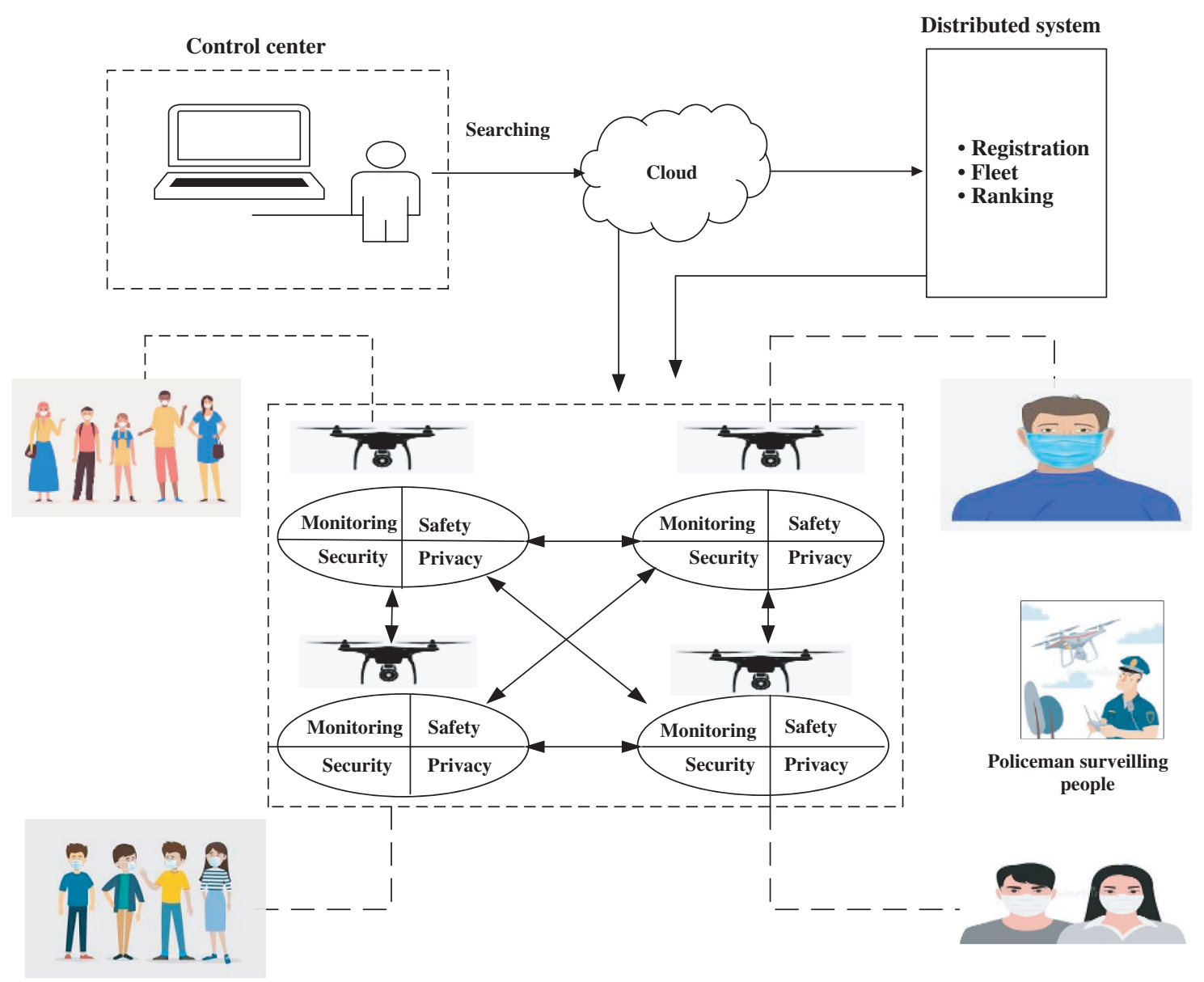

Figure 4: Surveillance architecture of the drone's network bases on IoT

\subsection{Healthcare Delivery Based on IoT Technologies}

\subsubsection{Technical Aspects of Healthcare Delivery Based on IoT Technologies}

For the medical industry, robotic devices are integrated devices that can perform duties by incorporating the fields of mechanics and electronics, such as the measurement of movements, force, domain, as well as sensors system technology among some other implementations of those fields. Patients care, patients 
monitoring, artificial prosthetics, medical interventions if needed, e-health services, and rehabilitation are examples of the duties that can be performed by the robots $[35,36]$.

\subsubsection{Healthcare Delivery Based on IoT Technologies in Malaysia}

Healthcare service delivery providers are committed to building instruments that can hand out medication by using a network of connected devices [37]. The robotic device named MCK19 or Makcik Kiah 19, it is the first Malaysian manufactured delivery robot aimed at assisting hospitals and healthcare providers in the delivery of healthcare to COVID-19 patients [38]. The project took off during the commencement of the movement control order (MCO). The robot has a carrying capacity up to $300 \mathrm{Kg}$ and the ability to autonomously navigate assisting medical staff in distribution of food, medicine, and other medical supplies required within the hospital environment. Using robots, MCK19 in particular can be seen as a proactive measure striving to reduce healthcare professional's exposure to patients under investigations (PUI), as shown in Fig. 5. It would also reduce the need for PPEs usage, which healthcare facilities are in shortage of. The robot's prototype's integrated modular storage compartment can be customized accordingly [38-40]. The main attributes of MCK19 are as per the following:

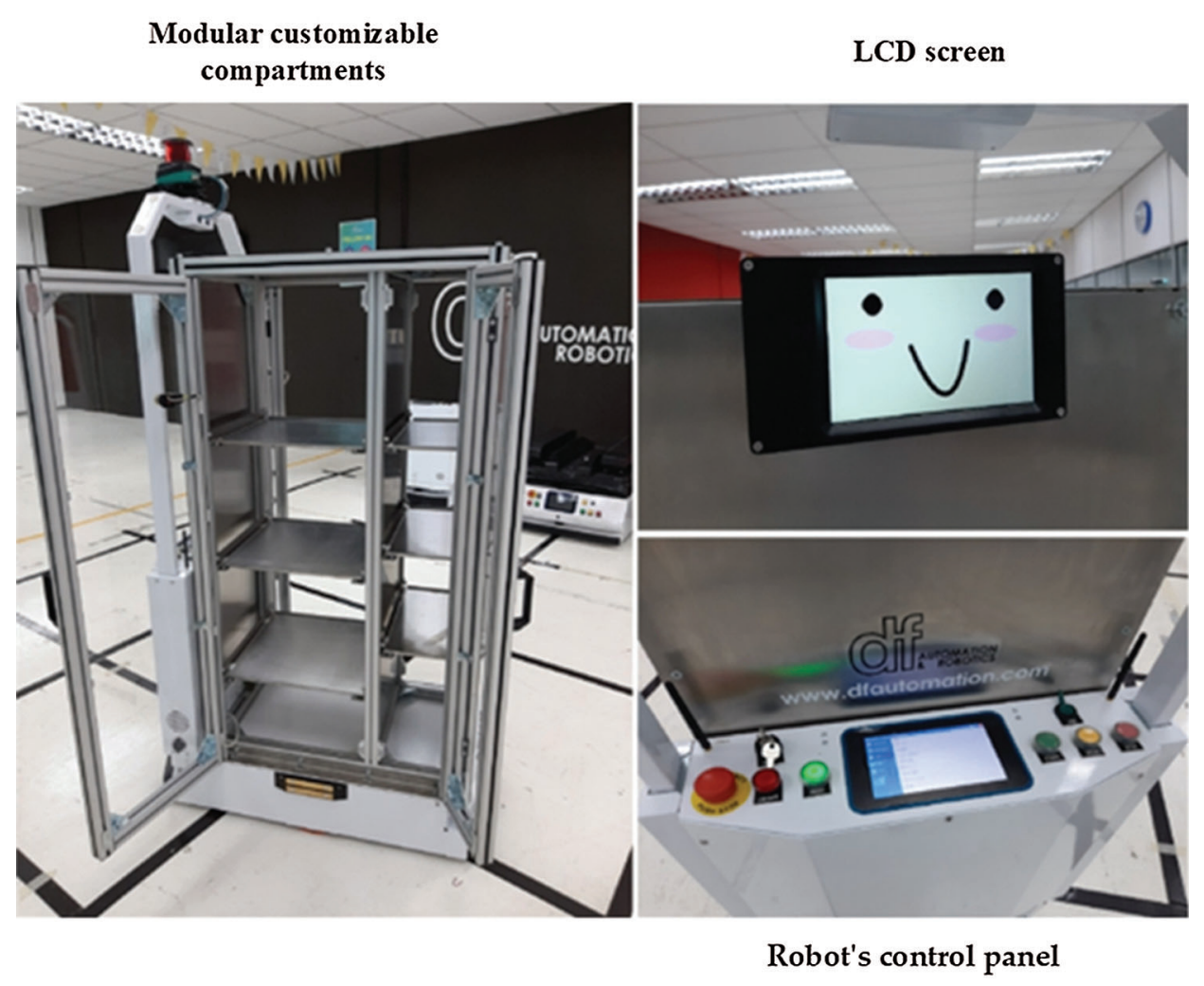

Figure 5: Makcik Kiah 19 robotic device

It is accessible through any computer device, tablet, or smartphone, allowing for remote accessibility and interaction with the robot.

Access is restricted only to authorized personnel.

The potential ability to be used for teleconferencing between medical professionals with their patients, through an LCD screen mounted on the robot's body. Currently, it is only displaying an animated face to make the robot more acceptable by users, as shown in Fig. 5. 


\section{Global IoT Technologies to Tackle COVID-19}

The demand to integrate IoT technologies in the healthcare sector is on the rise around the world. The quest to adopt the latest tools, to enable higher efficiency in tracking pathogens, early diagnosis, and treatment. Numerous IoT based technologies have been used worldwide to control, monitor, and to prevent the outbreak of COVID-19. This section aims to review the most prominent of these technologies.

\subsection{Tracking and Tracing Systems Based on IoT}

\subsubsection{The Technical Aspects of Tracking and Tracing Systems Based on IoT}

Currently, IoT in tracking and tracing system performs on three main technologies, as follows:

Global Positioning System (GPS) to obtain real-time information.

Radio-Frequency Identification (RFID) to control and track products.

On-Board Diagnostics (OBD II) to obtain maintenance data and system condition.

The procedure of an IoT based typical object tracking and tracing system is detailing in the following steps:

Object sensors, including OBD II sensors and GPS, would be used to collect location data.

By using mobile data connection, data from all sensors is periodically sent to the local gateway.

Gateway sends information to network server, where direction, location, speed, and other variables are collected and send to a secure application server in the cloud.

Application server sends alerts and reports alerts on movement and safety of the object to supervisor's mobile.

\subsubsection{Tracking and Tracing Systems Based on IoT in COVID-19 Application}

The tracking and tracing IoT based application's architecture is illustrated in Fig. 6 [41]. Recently, phone-based IoT tracking and tracing methods used in some other regions of the world have demonstrated promising potential in battling COVID-19. For instance, South Korea's attempt to limit the spread of COVID-19 by using a centralized tracking and tracing system illustrated how tracking and tracing IoT based mobile applications would be of a great impact on reducing the total number of infections [42,43]. Similarly, in Taiwan, an alarm system signaling when quarantined residents leave their residences by tracking their phone's radio signals $[43,44]$. In United States, Apple and Google companies are announcing the use of contact tracing by cooperating with health agencies to reduce the spread of COVID-19 outbreak [43,45,46].

In Singapore, track and traces assets based on IoT is implemented to battle the spread of COVID-19 outbreak by using real-time location tracking for medical equipment, surgical masks and sanitizers shipments [47]. Furthermore, the Center for Systems Science and Engineering at Johns Hopkins University has developed an IoT based real-time tracking map for COVID-19 cases tracking and tracing across the world. This tracking system was developed based on the data collected from Centers of Disease prevention and Control in the United States, Europe, and, China, as well as the WHO and other parties such as the DXY website. [48]. Tab. 1 illustrates the tracking and tracing systems based on IoT technologies for battling COVID-19 globally.

\subsection{Adoption IoT Technologies in Hospitals}

\subsubsection{The Technical Aspects of Adoption IoT Technologies in Hospitals}

In healthcare delivery based on IoT Technologies, the architecture network consists of physical devices and objects, which help to analyse, sense, and control remote devices. In this context, this network is highly 


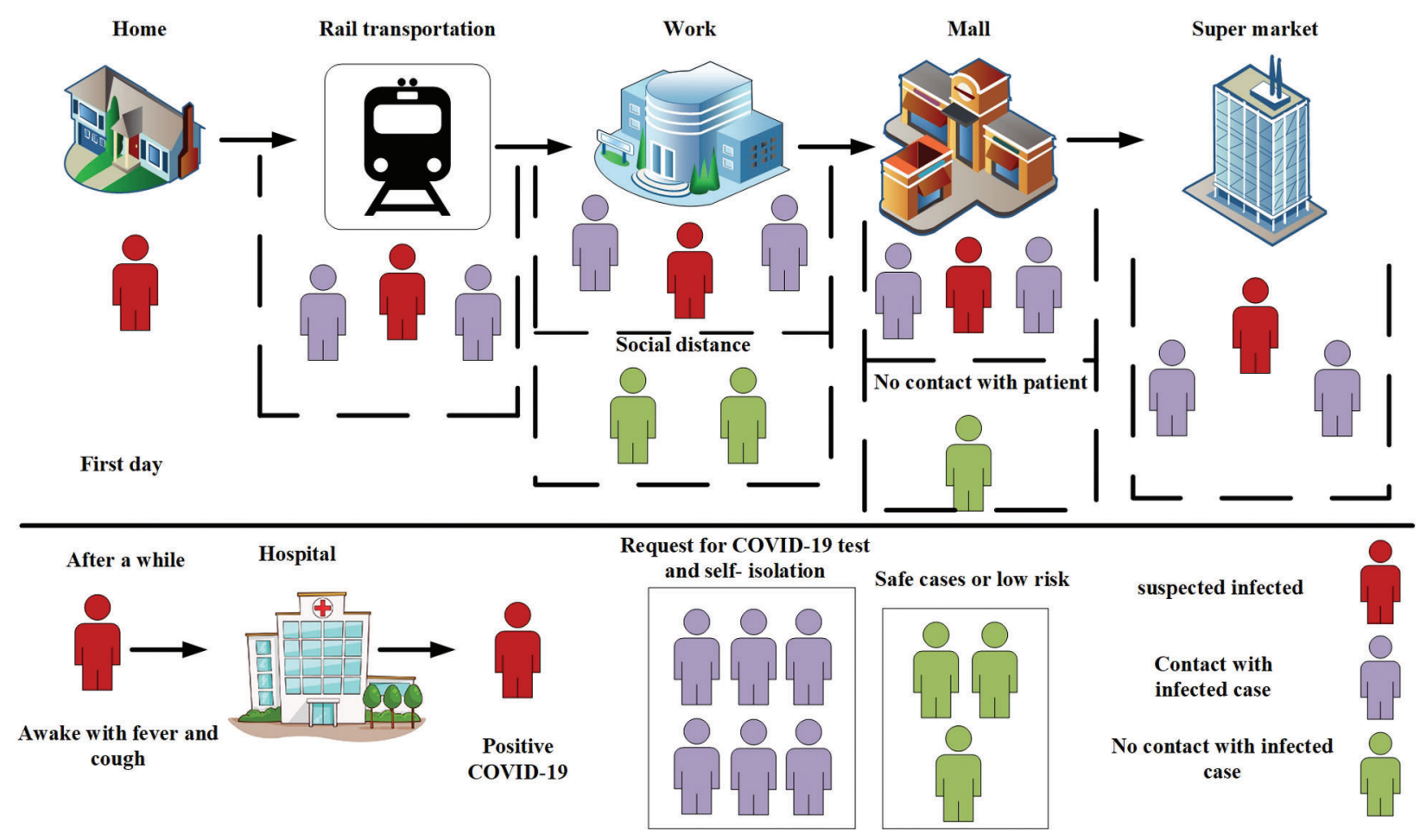

Figure 6: Architecture of IoT-based tracking and tracing platform

Table 1: The tracking and tracing systems based on IoT technologies for battling COVID-19 globally

\begin{tabular}{|c|c|c|c|c|}
\hline Ref. & Country & $\begin{array}{l}\text { Name of IoT } \\
\text { technology }\end{array}$ & Producer & Main features \\
\hline$[42,43]$ & $\begin{array}{l}\text { South } \\
\text { Korea }\end{array}$ & $\begin{array}{l}\text { Centralized data } \\
\text { collection } \\
\text { platform }\end{array}$ & $\begin{array}{l}\text { Ministries of } \\
\text { health-South } \\
\text { Korea }\end{array}$ & Tracking time to under $10 \mathrm{~min}$ per patient. \\
\hline [44] & Taiwan & Electronic fence & $\begin{array}{l}\text { Department of } \\
\text { cyber security- } \\
\text { Taiwan }\end{array}$ & $\begin{array}{l}\text { Rolling out a mobile phone-based that uses } \\
\text { location-tracking. }\end{array}$ \\
\hline$[46,47]$ & $\begin{array}{l}\text { United } \\
\text { States }\end{array}$ & $\begin{array}{l}\text { Bluetooth-based } \\
\text { contact tracing } \\
\text { platform }\end{array}$ & $\begin{array}{l}\text { Apple and } \\
\text { Google }\end{array}$ & $\begin{array}{l}\text { Enable interaction with a broader ecosystem of } \\
\text { apps and government health authorities. }\end{array}$ \\
\hline [47] & Singapore & $\begin{array}{l}\text { Crucial supplies } \\
\text { tracking }\end{array}$ & ASCENT & $\begin{array}{l}\text { Creation of geozones, where it receives alerts } \\
\text { and notifications when asset enter or exit } \\
\text { geozones. }\end{array}$ \\
\hline
\end{tabular}

dependent on the middleware layer in IoT architecture for information processing. The fundamental IoT architecture framed with three layers comprises of perception, transmission and application layers, which are then extended to have more layered architectures that includes middleware and business layer [5]. 
A. Perception layer: This layer describes physical objects and sensor devices, where the sensor device senses and identifies the object and gathers information about the object to be transmitted to the next layer for processing.

B. Transmission Layer: The major role of this layer to link different servers, network devices and smart objects. Besides, it transmits the sensor data from the perception layer to the middleware layer and vice versa through networks such as wireless, 3G, LAN, Bluetooth, and RFID.

C. Middleware Layer: It also called processing layer, which stores, analyses the large amount of information received from the transmission layer. It has the responsibility for the database connectivity and service management, where it connects with cloud computing, big data, and databases for processing the huge amount of data.

D. Application Layer: In this layer, the application-oriented services are delivered to the end users. This layer communicates directly with the end user by enabling application layer protocols.

E. Business Layer: The business layer controls the entire IoT eco-system with well-constructed efficient business models. It assists the end user to make decisions for further action.

\subsubsection{Adoption IoT Technologies in Hospitals for COVID-19 Applications}

As the hospital's resources being exerted, patients monitoring tools represent a great relief to various healthcare facilities ensuring effectiveness in service delivery. Monitoring devices allows healthcare workers to remotely provide their services without the need for their physical presence at each patients' exact location. Nursing staff may spend less time traveling between various locations inside the hospital. Remote monitoring can offer a great deal of assistance to all medical professionals and nursing staff, particularly in the hospital environment which can reduce the required physical effort spent by healthcare workers. With the novel COVID-19 virus now being declared a global pandemic, the importance of cleaning in public facilities has become paramount in the fight against the disease spreading even further, therefore, multiple IoT based technologies have been implemented to aid healthcare workers. For example, in Vancouver of British Colombia-Canada, hospitals are installing IoT buttons named Wanda Quicktouch, which are battery-powered, by Visionstate Corp, that alarms the hospital facility management department on maintenance and cleaning issues that might pose hazards to the public's safety $[49,50]$.

In times when a pandemic is spreading rapidly among the masses, monitoring patients' vital signs is of the essence in healthcare service delivery. Due to the contagious nature of the disease, each contact that takes place between healthcare providers and patients to gauge the patient's body temperature represent an increase in the risk of the medical professional contracting COVID-19. To overcome this problem, Aranet Medical Thermometer is used in some hospitals, where a single system set-up consists of an Aranet PRO100 base station and 100 wireless battery powered body temperature sensors [51-53]. Sensors send their readings to a central monitoring unit wirelessly once in a minute and this set up can notify medical staff when a case requires medical intervention, while each patient's historical data can be accessed. All the aforementioned functionalities can be obtained through a user-friendly mobile application. It is worth mentioning the fact that this sensor does not require regular calibration (medical sensor needs to be calibrated regularly) as it is calibrated from the manufacturer for a lifetime. Additionally, the Shanghai Public Health Clinical Center (SPHCC) makes use of IoT technologies and wearable sensing devices for COVID-19 patients' monitoring [54,55]. SPHCC is using VivaLNK's real-time temperature to monitor COVID-19 cases, which decreases the hazards of healthcare providers being infected by the virus. SPHCC stated that the usage of IoT Bluetooth based devices and Cassia Network's gateways as a solutions provider, combined with the application of VivaLNK's sensing device to surveil COVID-19 patients. VivaLNK's temperature sensing devices are employed to obtain a real-time monitoring capability of possible body temperature fluctuations. Cassia's gateways are used to collect 
patients' data in real-time, from the sensing devices and transmitting the collected readings to a healthcare professional's station. Cassia's Controller represents a powerful management technique, whereby if employed by medical staff to keep an eye on patients' vital signs it will help provide a comprehensive real-time reading. Cassia's gateways enable a maximum of 40 Bluetooth devices to be connected at a time while supporting a long-range connectivity that covers a large area in the SPHCC [55]. Finally, ABM Respiratory Care creates world's first IoT-enabled Tele-Ventilator for COVID-19 Pandemic in Singapore. ABM's Tele-Ventilator addresses both issues by enabling healthcare professionals to securely monitor and adjust ventilator settings through their online portal from any location [56,57]. Tab. 2 presents adoption IoT technologies in hospitals around the world for tackling the spread of COVID-19.

Table 2: The Adoption IoT technologies in hospitals globally for tackling the spread of COVID-19

\begin{tabular}{|c|c|c|c|c|}
\hline Ref. & Country & $\begin{array}{l}\text { Name of IoT } \\
\text { technology }\end{array}$ & Producer & Main features \\
\hline$[49,50]$ & Canada & $\begin{array}{l}\text { Wanda } \\
\text { Quicktouch }\end{array}$ & Visionstate Corp & $\begin{array}{l}\text { Issuing alerts for cleaning or maintenance } \\
\text { issues in the hospitals. }\end{array}$ \\
\hline [51-53] & Latvia & $\begin{array}{l}\text { Aranet Medical } \\
\text { Thermometer }\end{array}$ & Aranet & $\begin{array}{l}\text { The historical data can be viewed for each } \\
\text { individual patient, as well as alerts can be set } \\
\text { up to inform the medical staff of the most } \\
\text { acute cases that require immediate attention. }\end{array}$ \\
\hline$[54,55]$ & China & $\begin{array}{l}\text { Bluetooth-based } \\
\text { contact tracing } \\
\text { platform }\end{array}$ & $\begin{array}{l}\text { Shanghai Public } \\
\text { Health Clinical } \\
\text { Center (SPHCC) }\end{array}$ & $\begin{array}{l}\text { It is used by medical staff to monitor patients } \\
\text { and to provide a holistic view of their vitals } \\
\text { in real-time. }\end{array}$ \\
\hline$[56,57]$ & Singapore & $\begin{array}{l}\text { ABM's Tele- } \\
\text { Ventilator }\end{array}$ & $\begin{array}{l}\text { ABM Respiratory } \\
\text { Care }\end{array}$ & $\begin{array}{l}25 \text { times faster and creates } 50 \text { times less data } \\
\text { traffic than traditional web technologies. }\end{array}$ \\
\hline
\end{tabular}

\subsection{Self-Monitoring Devices Based on IoT}

\subsubsection{The Technical Aspects of Self-Monitoring Devices Based on IoT}

Wearable IoT (WIoT) can be defined as a technological infrastructure that interconnects wearable sensors to enable monitoring human factors including health, wellness, behaviours and other data useful in enhancing individuals' everyday quality of life. The interconnections between WIoT components are described in the following sections:

\section{Wearable Body Area Sensors (WBAS)}

WBAS can be described as a fronted component that unobtrusively envelops the body to capture healthcentric data. WBAS is used for collecting the data either directly from the body through contact sensors or from peripheral sensors providing indirect information of body and its behaviours. Besides, it prepares the data for either on-board analysis for close-loop feedback or remote transmission for comprehensive analysis and decision support.

\section{Internet-Connected Gateways}

Gateway devices comprise of short-range communication technology such as Bluetooth, used to exchange data with wearable sensors, and of heterogeneous networks, such as Wi-Fi and GSM, used to send the data to the cloud. Some Gateway devices have the capacity to store data, to run some preprocessing algorithms evaluating whether the data is clinically relevant, and to send the data intermittently to remote servers. 


\section{Cloud and Big Data Support}

The congruence of close companions - wearable sensors and smartphones - will flood the cloud centres with medical data at an unprecedented rate. Gaining knowledge from this data is as important as acquiring the information from the body. Patients only benefit from wearing sensors when intelligent algorithms process the data and offer some actions to take.

\subsubsection{Self-Monitoring Devices Based on IoT in COVID-19 Applications}

Fig. 7 presents an IoT based generic framework of self-monitoring consisting different types of sensing, communication, and control devices [58]. Medical home located IoT devices are already in use in improving outpatient facilities services delivery and reducing periodic appointments. The advantages of medical home located IoT devices during a pandemic are more evident. An IoT based medication control is effective in reducing the pressure off medical staff, by regularly alerting patients on their medication dose timing and supporting them to maintain accordance. It provides healthcare workers with a real-time registry of patient's medication routines and tracks patient's recovery by connectedness to medical records.

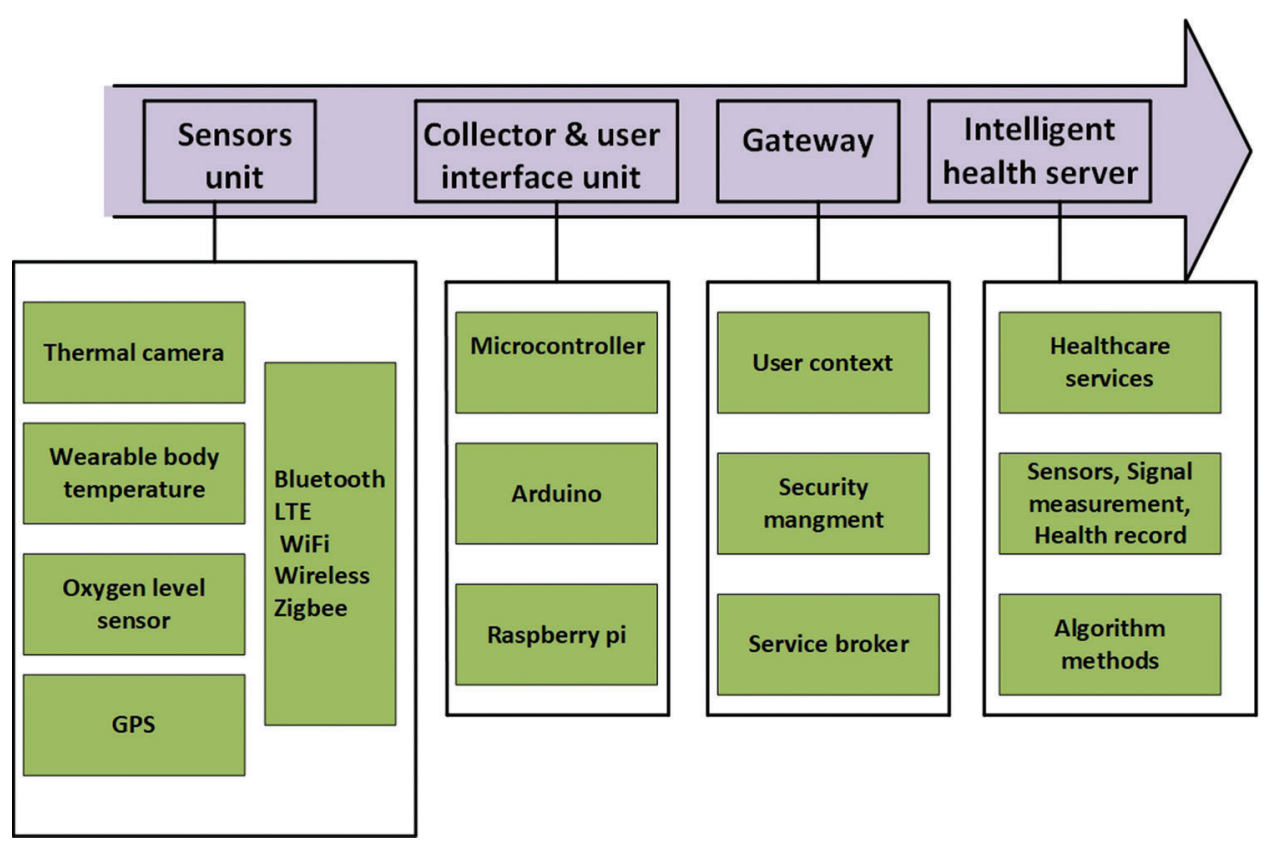

Figure 7: A generic framework for self-monitoring based IoT system [58]

It is crucial for patients at risk of struggling to maintain regular medication routines. Maintaining an orderly routine of medication is necessary in all cases. However, when the medical system is stressed out and pushed to the limits of its capabilities, ensuring that medical assistance of home staying patients is not necessary can be a major relief. In order to integrate self-monitoring devices based on IoT technologies which would be used for curbing COVID-19 outbreak, the authors in [59] proposed a generic framework of self-monitoring devices based on IoT for tackling COVID-19 pandemic, as shown in Fig. 8. Multiple self-monitoring devices based on IoT have been applied to reduce the spread of COVID-19 pandemic. For example, a Citizen App-based-IoT allows individuals to both contribute and access critical information, empowering them to collaborate with the government to actively flatten the curve. The Citizen App enables users to perform health self-assessments, self-report, and self-monitor if home quarantined. 


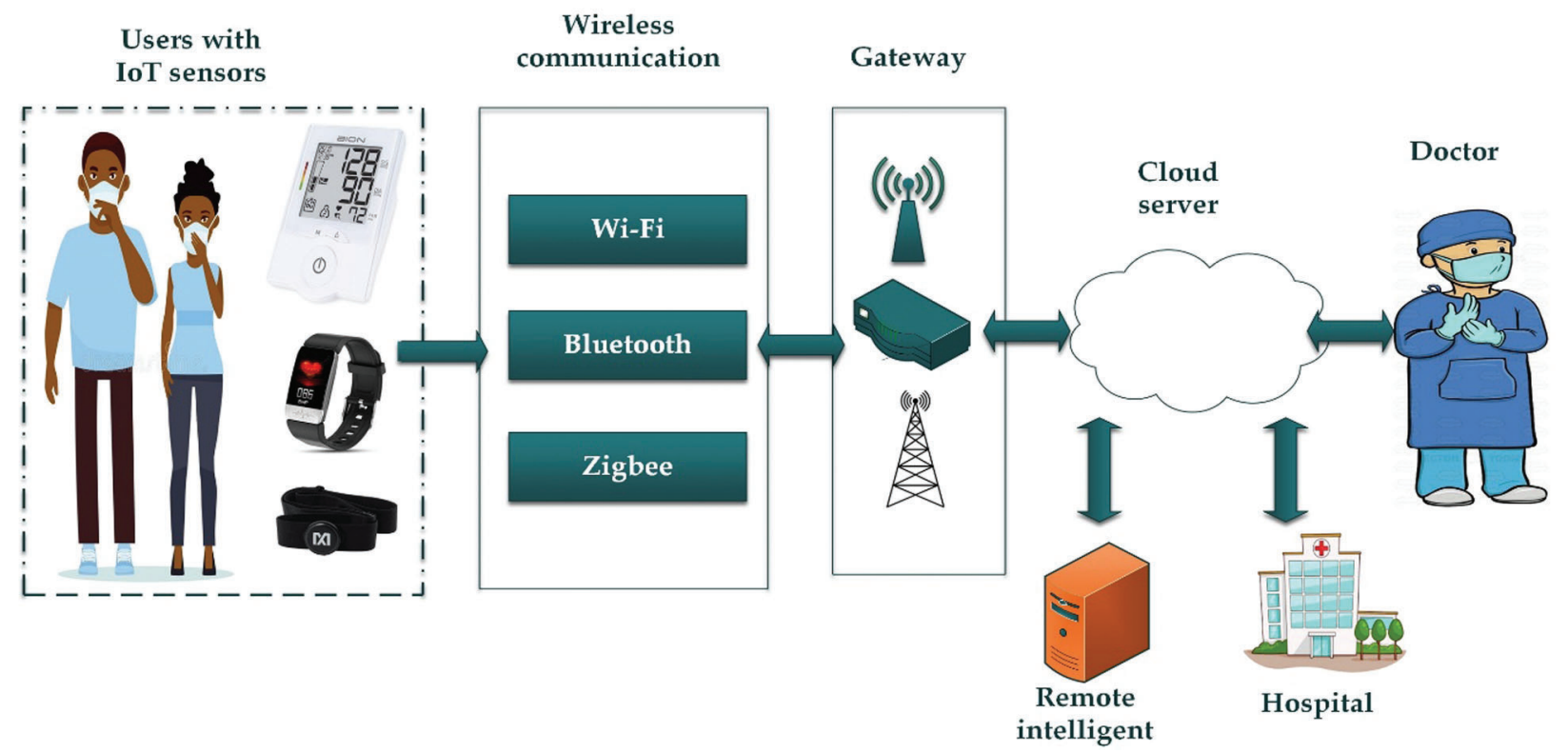

Figure 8: Self-monitoring system made possible by incorporating Internet of Things (IoT) technologies

\section{Challenges and Recommendations}

To corporate with Malaysia's effort in handling and controlling COVID-19 pandemic, the global IoT technologies (as detailed in Section 4) would be integrated into the current IoT technologies that are being implemented in Malaysia (as explained in Section 3). But this integration rises some issues and challenges that required to be addressed in this section. Here are six of those challenges faced by healthcare providers in the COVID1-19 outbreak along with possible recommendations (see Tab. 3) on what practitioners would be able to manage when they apply IoT technologies in Malaysia.

\subsection{Construction of IoT Technologies in Malaysia}

The main challenge for the construction of IoT technology in Malaysia is the integration of various network technologies in public IP networks to ensure scalable and reliable network communication [60]. With the increase of IoT technology deployment, each sector is required to consider their networking elements to ensure the efficient data transmission between the wired and wireless networks. IoT relies on connectivity and reliability to communicate for future internet architecture [61].

\subsection{High Cost of IoT Deployments}

Implementing the IoT can be expensive due to the costs of purchasing all the required hardware and software including the cost for network infrastructure. This also includes the cost after developing devices, cost for implementation and maintenance that are needed to ensure the interoperability of the devices [62]. Malaysia relies on the access planning of IoT devices with a centralized cloud-based business model [63]. This method results in many years of expenditures or maybe even decades without profit.

\subsection{Privacy and Data Security}

Using IoT can compromise users' privacy and data security, for example the safety of real-time data mobility Accessing the data collected by the IoT devices without authorization may originate a serious 
hazard to patients' physical well-being and their personal information. The potential risk of connected devices such as mobile devices and medical devices wearable pose risks during collection, transferring and processing of personal medical information. The personal information is also vulnerable on saved registries of medical history on cloud based or physical servers that is able to be accessed by authorized personnel. [64].

Cyber-attacks are seen as a serious threat in health-care systems. Occurring Denial of Service (DoS) attacks may impact patients' safety. A regular defense against DoS attacks is built in system redundancy whereby multiple devices on the network may require digital authentication. In health-care settings, duplicating resources is sometimes out of reach due to the fact that some of these instruments are instilled inside life-critical systems. A quick detection of potential security compromise through unauthorized system access which may pose some serious safety and security threats remains a challenging frontier due to multiple software and hardware complex issues and vulnerabilities $[65,66]$.

Confidentiality and privacy are important concerns for physicians as well. Patients may not be comfortable with sharing their medical history due to the sensitive essence of health data (for example, HIV or cancer test results). Concerns exist that the integration of connected technology into current medical information systems may compromise the confidentiality of health data [67].

\subsection{Standards and Regulations}

Users and healthcare workers both necessitate harmonic operability within the domain of IoT applicability, which inspires a challenging complexity due to the diverse fields interoperating within the IoT technology framework. There is an apparent need for the process to be regulated by a diverse set of regulatory agencies that possesses the technical prowess to do so. These complexities are more aggravated in connected settings whereby medical regulations require particular rigorous regulation process [68].

\subsection{Talent and Workers}

Intelligent healthcare systems are not intuitive to use by physicians. Numerous functions could increase systems complexity, and thereby decrease caregiver's eagerness to learn the system full features [69]. There is also a need to prepare the workforce for the future in IoT. Educational institutions need to be equipped with relevant syllabus and facilities for the growth of IoT professionals. This institution must be able to generate producers and suppliers, not only consumers of technology. Learning institutions also need to provide a strong foundation for science and engineering students and enhance it further in order to produce solid IoT professionals.

\subsection{Data Collection and Management}

Healthcare systems that employ IoT sensing technology is facing multiple challenges on how the data originated. Through the aggregating patients' medical data, the data is collected via sensing devices which must be managed accordingly. Due to the continuously changing status of the human body, the produced data via those sensing devices varies accordingly. Moreover, IoT healthcare settings necessitate that their design is to be driven by an implementation of an appropriate learning techniques that are data-driven to address its variable cyber-physical constituents. An appropriate data analysis can provide useful information regarding patients' health status [70]. 
Table 3: Adoption of IoT technologies in healthcare for coping COVID-19 in Malaysia: challenges and recommendations

\begin{tabular}{|c|c|}
\hline Challenges & Recommendations \\
\hline $\begin{array}{l}\text { Construction of IoT } \\
\text { technologies in Malaysia }\end{array}$ & $\begin{array}{l}\text { Attract, build and maintain leading skills in IoT technologies and improve } \\
\text { small and medium enterprises to the next level in IoT space while, } \\
\text { strengthening the industry's ability to maintain robust economic } \\
\text { performance for new IoT technologies [71]. Moreover, facilitate the } \\
\text { private sectors in developing and deploying IoT technology that is cost- } \\
\text { effective. }\end{array}$ \\
\hline High cost of IoT deployments & $\begin{array}{l}\text { Cost is a major obstacle to small and medium-sized businesses in } \\
\text { realizing IoT usage in field ICT [72]. Therefore, it is recommended that } \\
\text { the Government provide a financial or special fund to motivate and utilize } \\
\text { IoT for future development and achievements. Industries can compete } \\
\text { with each other for providing good services towards the IoT. }\end{array}$ \\
\hline $\begin{array}{l}\text { Security of data and privacy } \\
\text { protection }\end{array}$ & $\begin{array}{l}\text { Employment of lightweight cryptographic algorithms that can be } \\
\text { implemented on resource-constrained IoT devices connected via low- } \\
\text { energy networks. Data protection during the collection, storage, and } \\
\text { transfer processes. } \\
\text { Development of password enforcement policies, secure pairing protocols, } \\
\text { and secure transmission mechanisms. Design of new and improved key } \\
\text { sharing mechanisms for implementing symmetric key encryption. }\end{array}$ \\
\hline $\begin{array}{l}\text { Medical standards and } \\
\text { regulations }\end{array}$ & $\begin{array}{l}\text { Companies that want to build IoT applications in the medical area must } \\
\text { consider the standards and regulations imposed by medical sector. The } \\
\text { primary objective of such effort is to develop a standardized way to } \\
\text { express the contract, trust, process, workflow, message, and other data } \\
\text { semantics. }\end{array}$ \\
\hline Talent and workers & $\begin{array}{l}\text { Providing training, workshops, and seminar for healthcare workers to be } \\
\text { familiar with IoT advance technologies. Moving forward, the education } \\
\text { industry could give rise to potential talents able to build better solutions } \\
\text { for the future. Also, guidelines and policies in defining the ownership of } \\
\text { information, privacy and security must be implemented to gain market } \\
\text { confidence towards the deployment IoT in Malaysia. }\end{array}$ \\
\hline $\begin{array}{l}\text { Collection and management } \\
\text { of data }\end{array}$ & $\begin{array}{l}\text { Use of efficient data analysis tools and intelligent learning algorithms } \\
\text { such as Artificial Neural Network (ANN) and Genetic Algorithms (GA). } \\
\text { In addition, Various distributed computing platforms are being used today } \\
\text { for big data analytics. These platforms include Apache Samza, Apache } \\
\text { Spark, Hadoop MapReduce, Apache Storm and Flink. Hadoop } \\
\text { MapReduce and Apache Spark are the most widely used platforms for } \\
\text { massive data storage and analysis challenges [73]. }\end{array}$ \\
\hline
\end{tabular}

\section{Impact of IoT Applications on Mitigating the Spread of COVID-19}

As discussed, the Internet of Things concept utilizes the interconnected network for the effective flow and exchange of data. It also enables social workers, patients, civilians, etc. to be in connection with the service benefactors for discussing any issue and cooperation. Therefore, by employing the proposed IoT 
tactic in COVID-19 pandemic, the effective tracing of patients, as well as the suspicious cases, can be completely assured. By developing a well-informed group of into a connected network, cluster identification can be more effective [74-77]. Providing contact free healthcare services by incorporating IoT based technologies in medical practices can have a psychological relief to both patients and service providers as well as the potential impact on limiting the number of infections occurring within hospitals' premises [76]. According to a study by researchers at MIT, overlaying geographic information system (GIS) on IoT mobile data can assist epidemiologists in their search for patient zero and can help identify all the people who have come into contact with the infected patients. The technology can also be helpful in monitoring patients who are high-risk and hence can be a source of information to healthcare staff to take adequate action [78].

\section{Proposed IoT Integration Framework to Cope with COVID-19 Spread}

The literature review performed in this review paper focused on identifying important parameters which are constitutes the building blocks of the proposed framework. In this section, the authors present a generic framework that details a prospective integrated structure for IoT technologies adoption and evaluation associated with the contemporary issues in fighting COVID-19 outbreak. This framework aims to develop an outline of three phases that can serve as a reference for future research to use IoT technologies for fighting COVID-19 in Malaysia and worldwide. As illustrated in Fig. 9a detailed description of these phases includes the following:

Phase one: This phase represents the input of the framework which comprises COVID-19 contaminants factors with IoT technologies. In addition, an assessment of these technologies usage and their properties is carried out to ensure an impactful selection of these technologies and their best implementation practices.

Phase two: There are 12 imbedded major IoT applications which could be used to contain the outbreak of COVID-19 pandemic. These applications could be carried out by utilizing the aforementioned IoT technologies (as described in Section 3 and, Section 4). The implementation of these technologies may initiate various issues and challenges which are represented in the second phase.

Phase three, Results/output: A successful implementation of these technologies, can promote an improvement in the efficacy of healthcare providers by a reduction in the imposed workload. Additionally, a number of beneficial health outcome can be derived as a result of reducing the chances of malpractice, providing a superior treatment, effective case control through real-time monitoring of patients, improving the accuracy of diagnosis, and potentially lowering the underlying expenses from healthcare facilities point of view.

\section{Limitations of the Study}

The study findings are limited by analyzing articles published within the investigated and targeted timeframe of the study to ensure the most recent published articles were collected. Articles published after the date of 31st of June, 2020 in which the articles were searched, found and collected are not included in this study. Therefore, there might have been a new set of implementation strategies of IoT technologies in various regions, carried out between the time of submitting this article and time of publication. Furthermore, this study's selected keywords focuses on devising a generic framework to ensure a smooth implementation of IoT technologies that was not implemented in a country (Malaysia in this research) taking into account potential locally faced challenges to the implementation process, and, since each country/region has its own within this procedures, a set of unique challenges that have not been discussed in this article may rise. Furthermore, the extent of the challenges mentioned in the 


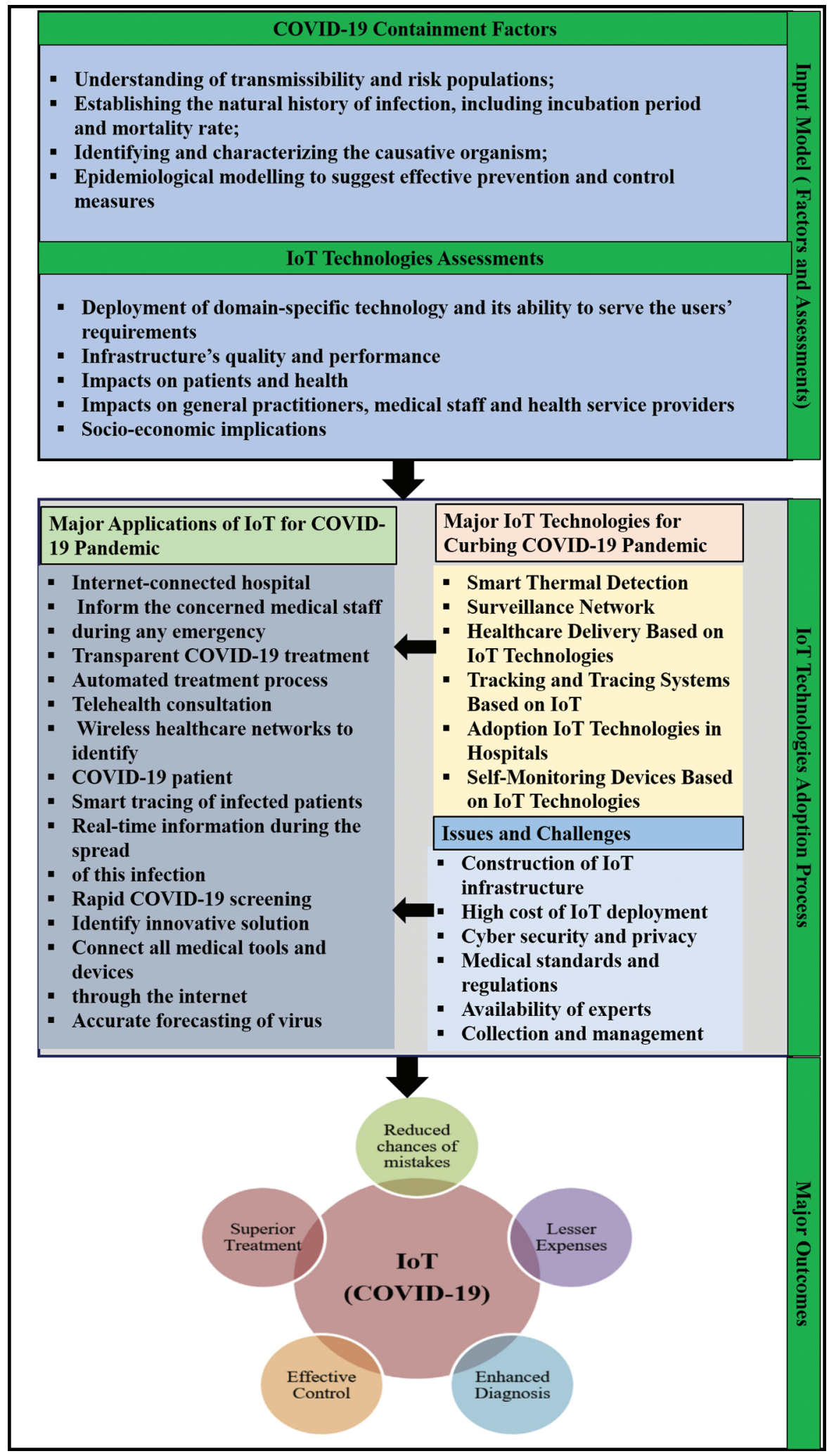

Figure 9: A conceptual framework to accelerate the battle pace with spread of COVID-19 
previous section should be empirically tested according to the respective location where the implementation process is carried out.

\section{Recommendations and Conclusions}

A set of recommendations have been suggested by the authors to further expedite the COVID19 curbing process by implementing IoT technologies that are applicable in both local and global cases, were formed and presented as per the following:

- The authors of this paper suggest that while there have been implementations of IoT technologies in Malaysia especially in early detection and tracing and tracking, the incorporation of more IoT based technologies in more sectors is suspected to yield better results. Furthermore, implementation initiatives that cover more than just urban areas would offer more accurate estimations of the situation in terms of detecting suspected isolated cases in rural and semi-urban areas.

- Globally, while IoT technology have been available for implementations in healthcare institutions, some of these technologies are still considered expensive especially for developing countries. The authors suggest that integrating IoT devices in healthcare services and facilities such as, remote monitoring equipped patients' beds and having them streaming real-time data to nursing stations would be the most impactful, especially in terms of minimizing physical contact. This can potentially limit the number of the hospital acquired infections, which may ensure a resilient healthcare service that is vital.

- Reports attempting to curb the spread of the COVID-19 infections using IoT technologies are on the rise, with reports of promising results. Therefore, the authors hypothesized that populating the publics daily lives with more means of early detection, tracing and tracking can only be helpful regardless of the setting.

This paper provides a comprehensive review of IoT technologies and approaches for tackling COVID-19 pandemic in Malaysia. In addition, IoT technologies that are implemented globally for coping COVID are reviewed in this manuscript. The major IoT technologies of helping in early detection of thermal abnormalities, such as SITD Solution and EWAR are discussed in this paper. In this respect, the potential features of these technologies are highlighted in this review. Moreover, drones equipped with cameras and loudspeaker based on surveillance network are presented in this paper, where these drones are considered an important tool in coping the spread of the COVID-19 disease. In this context, loudspeakers are serving as an auditory announcement device whereby individuals can be advised against mass gatherings and roaming contaminated zones. In addition, this paper discusses the most prominent of IoT technologies that are used to control, monitor, and to prevent the outbreak of COVID-19 globally. In this respect, the most potential IoT approaches, which include tracking and tracing systems, smart technologies in hospitals, and self-monitoring devices that are applied to tackle COVID-19 globally are briefly review in this paper. However, these approaches bring with them challenges that's needs to be overcome to be applied in Malaysia for tackling COVID-19. In this review, six of those challenges faced by healthcare community in the COVID-19 pandemic along with possible recommendations for what practitioners would be able to manage when they apply IoT technologies in Malaysia are presented.

Funding Statement: This work was supported by Universiti Tenaga Nasional BOLD Publication Fund code number RJO10436494/iRMC/Publication/2019.

Conflicts of Interest: The authors declare no potential conflict of interest. 


\section{References}

[1] C. Sohrabia, Z. Alsafib, N. O’Neilla, M. Khanb, A. Kerwanc et al., "World health organization declares global emergency: A review of the 2019 novel coronavirus (COVID-19)," International Journal of Surgery, vol. 76, no. 4, pp. 71-76, 2020.

[2] Z. Ye, Y. Zhang, Y. Wang, Z. Huang and B. Song, "Chest CT manifestations of new coronavirus disease 2019 (COVID-19): A pictorial review,” European Radiology, vol. 30, no. 8, pp. 4381-4389, 2020.

[3] M. A. Mohammed, K. H. Abdul Kareem, A. S. Al-Waisy, S. A. Mostafa, S. Al-Fahdawi et al., "Benchmarking methodology for selection of optimal COVID-19 diagnostic model based on entropy and TOPSIS methods," IEEE Access, vol. 8, pp. 99115-99131, 2020.

[4] R. Y. Zhong, X. Xua, E. Klotz and S. T. Newmanc, "Intelligent manufacturing in the context of industry 4.0: A review," Engineering, vol. 3, no. 5, pp. 616-630, 2017.

[5] P. Sethi and S. R. Sarangi, "Internet of Things: Architectures, protocols, and applications," Journal of Electrical and Computer Engineering, vol. 2017, no. 1, pp. 1-25, 2017.

[6] S. He, "Using the Internet of Things to fight virus outbreaks," 2020. [Online]. Available: https://www. technologynetworks.com/immunology/articles/using-the-internet-of-things-to-fight-virus-outbreaks-331992.

[7] A. M. Rahmani, T. N. Gia, B. Negash, A. Anzanpour, I. Azimi et al., "Exploiting smart e-health gateways at the edge of healthcare Internet-of-Things: A fog computing approach," Future Generation Computer Systems, vol. 78, no. 1, pp. 641-658, 2018.

[8] A. Mavrogiorgou, A. Kiourtis, K. Perakis, S. Pitsios and D. Kyriazis, "IoT in healthcare: Achieving interoperability of high-quality data acquired by IoT medical devices," Sensors, vol. 19, no. 9, pp. $1978,2019$.

[9] A. A. Mutlag, M. K. Abd Ghani, N. A. Arunkumar, M. A. Mohammed and O. Mohd, "Enabling technologies for fog computing in healthcare IoT systems," Future Generation Computer Systems, vol. 90, no. 1, pp. 62-78, 2019.

[10] S. A. Mostafa, S. S. Gunasekaran, A. Mustapha, M. A. Mohammed and W. M. Abduallah, "Modelling an adjustable autonomous multi-agent internet of things system for elderly smart home," in Int. Conf. on Applied Human Factors and Ergonomics, San Diego, CA, USA, pp. 301-311, 2019.

[11] E. Massaro, D. Kondor and C. Ratti, "Assessing the interplay between human mobility and mosquito borne diseases in urban environments," Scientific Reports, vol. 9, no. 1, pp. 1-13, 2019.

[12] V. Chamola, V. Hassija, V. Gupta and M. Guizani, "Comprehensive review of the COVID-19 pandemic and the role of IoT, drones, AI, blockchain and 5G in managing its Impact," IEEE Access, vol. 8, no. 1, pp. 90225-90265, 2020.

[13] R. P. Singh, M. Javaid, A. Haleem and R. Suman, "Internet of Things (IoT) applications to fight against COVID-19 pandemic," Diabetes \& Metabolic Syndrome: Clinical Research \& Reviews, vol. 14, no. 4, pp. 521-524, 2020.

[14] L. Shan, C. Pei and Y. Tinany, "Internet of Things (IOT) development for the promotion of information economy," in APEC Telecommunications and Information Working Group, Heng Mui Keng Terrace, Singapore, pp. 1-36, 2015.

[15] R. Gunasagaran, L. M. Kamarudin, A. Zakaria, E. Kanagaraj, M. M. Alimon et al., "Internet of Things: Sensor to sensor communication," in IEEE SENSORS, Busan, South Korea, pp. 1-4, 2015.

[16] K. L. A. Yau, S. L. Lau, H. N. Chua, M. H. Ling, V. Iranmanesh et al., "Greater Kuala Lumpur as a smart city: A case study on technology opportunities," in 8th Int. Conf. on Knowledge and Smart Technology, Chiangmai, Thailand, pp. 96-101, 2016.

[17] M. Berhad, "Why Internet of Things (IoT), " in National Internet of Things (IoT) Strategic Roadmap, 1st. edition, Kuala Lumpur, Malaysia: MIMOS Berhad, pp.1-14, 2015.

[18] A. D. H. Dharfizi, “The energy sector and the Internet of Things-sustainable consumption and enhanced security through industrial revolution 4. 0," Journal of International Studies, vol. 14, no. 1, pp. 99-117, 2020.

[19] Y. H. Sue, "Driving digitalization ecosystems in ASEAN. Asia IoT business platform," 2019. [Online]. Available: http://iotbusiness-platform.com/blog/intelligent-transport-for-malaysias-smart-city-vision/. 
[20] Malaysia Smart City Framework, "Ministry of housing and local government," 2018. [Online]. Available: https:// www.kpkt.gov.my/resources/index/user_1/GALERI/PDF_PENERBITAN/FRAMEWORK/FRAMEWORK_ SMART_CITY_FINAL_REPORT_190328.pdf.

[21] H. Mora, D. Gil, R. M. Terol, J. Azorín and J. Szymanski, “An IoT-based computational framework for healthcare monitoring in mobile environments," Sensors, vol. 17, no. 10, 2302, 2017.

[22] D. S. W. Ting, L. Carin, V. Dzau and T. Y. Wong, "Digital technology and COVID-19," Nature Medicine, vol. 26, no. 4, pp. 459-461, 2020.

[23] L. Bai, D. Yang, X. Wang, L. Tong, X. Zhu et al., "Chinese experts' consensus on the Internet of Things-aided diagnosis and treatment of coronavirus disease 2019," Clinical eHealth, vol. 3, no. 1, pp. 7-15, 2020.

[24] C. Ma, N. T. Trung, H. Uchiyama, H. Nagahara, A. Shimada et al., "Adapting local features for face detection in thermal image," Sensors, vol. 17, no. 12, pp. 2741, 2017.

[25] M. Vollmer and K. P. Möllmann, Infrared thermal imaging: fundamentals, research and applications. 1st ed. Hoboken, NJ, USA: John Wiley \& Sons, 2010.

[26] H. Claude, "How smarter AI-powered cameras can mitigate the spread of Wuhan novel coronavirus (COVID-19), and what we've learned from the SARS outbreak 17 years prior," 2020. [Online]. Available: https://anyconnect. $\mathrm{com} / \mathrm{blog} / \mathrm{smart}$-thermal-cameras-wuhan-coronavirus.

[27] HKBN Enterprise Solutions, "HKBN enterprise solutions launches cost-effective and fast-to-deploy smart IoT thermal detection solution for retailers and businesses amid Coronavirus threat," 2020. [Online]. Available: https:/en.prnasia.com/releases/apac/hkbn-enterprise-solutions-launches-cost-effective-and-fast-to-deploy-smartiot-thermal-detection-solution-for-retailers-and-businesses-amid-coronavirus-threat-275437.shtml.

[28] The edge markets, "Mitigating COVID-19 infection risks in your premises," 2020. [Online]. Available: https:// www.theedgemarkets.com/content/advertise/mitigating-covid-19-infection-risks-in-your-premises.

[29] New straits times, "TM unveils solution for COVID-19 early detection," 2020. [Online]. Available: https://www. nst.com.my/news/nation/2020/04/581027/tm-unveils-solution-covid-19-early-detection.

[30] C. COMM, "TM unveils EWAR, its latest solution for COVID-19 early detection! TM research \& development," 2020. [Online]. Available: https://www.tmrnd.com.my/tm-unveils-ewar-its-latest-solution-for-covid-19-earlydetection/.

[31] Lanner, "4 Smart video surveillance trends you will see in,” 2019. [Online]. Available: https://www.lanneramerica.com/blog/4-smart-video-surveillance-trends-you-will-see-in-2020/.

[32] A. Kharpal, "Use of surveillance to fight coronavirus raises concerns about government power after pandemic end," 2020. [Online]. Available: https://www.cnbc.com/2020/03/27/coronavirus-surveillance-used-bygovernments-to-fight-.

[33] M. A. Mokhtar, “COVID-19: Using drones to enforce EMCO,” 2020. [Online]. Available: https://www.nst.com. my/news/nation/2020/03/579632/covid-19-using-drones-enforce-emco.<span[1].

[34] The Star, "Eye in the sky: Drones proving a valuable tool in MCO enforcement," 2020. [Online]. Available: https://www.thestar.com.my/news/nation/2020/04/23/eye-in-the-sky-drones-proving-a-valuable-tool-in-mcoenforcement.

[35] M. Butter, A. Rensma, J. Boxsel, S. Kalisingh and M. Schoone, "Robotics for healthcare-final report," 2008. [Online]. Available: https://www.academia.edu/17543578/Robotics_for_healthcare_final_report.

[36] P. P. Ray, "Internet of robotic things: Concept, technologies, and challenges," IEEE Access, vol. 4, no. 1, pp. 9489-9500, 2016.

[37] P. P. Reid, W. D. Compton, J. H. Grossman and G. Fanjiang, "Information and communications systems: The backbone of the health care delivery system," in Building a Better Delivery System: A New Engineering/ Health Care Partnership, 1st ed., Washington (DC), US: National Academies Press, pp. 276, 2005.

[38] F. Nabihah, "Utm, Hctm \& Df Automation develop hospital delivery robot 'Makcik Kiah 19' to ace COVID-19. [Online]. Available: https://news.utm.my/2020/04/utm-hotm-df-automation-develop-hospital-delivery-robotmak-cik-kiah-19-to-ace-covid-19/.

[39] A. Wong, "Makcik Kiah ready to serve COVID-19 patients, no PPE required," 2020. [Online]. Available: https:// www.soyacincau.com/2020/04/13/utm-df-automation-makcik-kiah-autonomous-robot-covid-19/. 
[40] W. My, "Robot 'Makcik Kiah' dibangunkan bagi membantu petugas barisan hadapan,” 2020. [Online]. Available: https://angah.net/robot-makcik-kiah-dibangunkan-bagi-membantu-petugas-barisan-hadapan/..

[41] L. Ferretti, C. Wymant, M. Kendall, L. Zhao, A. Nurtay et al., "Quantifying SARS-CoV-2 transmission suggests epidemic control with digital contact tracing," Science, vol. 368, no. 6461, pp. 1-13, 2020.

[42] M. Zastrow, "South Korea is reporting intimate details of COVID-19 cases: has it helped?," 2020. [Online]. Available: https://www.nature.com/articles/d41586-020-00740-y.

[43] K. C. Tofel, "Here's how Apple and Google are working together for a phone-based COVID-19 track and trace," 2020. [Online]. Available: https://staceyoniot.com/heres-how-apple-and-google-are-working-together-for-aphone-based-covid-19-track-and-trace-solution/.

[44] M. Hui, "How Taiwan is tracking 55,000 people under home quarantine in real time," 2020. [Online]. Available: https://qz.com/1825997/taiwan-phone-tracking-system-monitors-55000-under-coronavirus-quarantine/.

[45] F. Sainz, "Apple and Google partner on COVID-19 contact tracing technology,” 2020. [Online]. Available: https:// www.apple.com/newsroom/2020/04/apple-and-google-partner-on-covid-19-contact-tracing-technology/.

[46] Google, "The keyword. Apple and Google partner on COVID-19 contact tracing technology," 2020. [Online]. Available: $\quad$ https://blog.google/inside-google/company-announcements/apple-and-google-partner-covid-19contact- tracing-technology/.

[47] Ascent, "COVID-19 tracking solutions," 2020. [Online]. Available: https://www.myascents.com/covid-19tracking-solutions/.

[48] M. K. N. Boulos and E. M. Geraghty, "Geographical tracking and mapping of coronavirus disease COVID-19/ severe acute respiratory syndrome coronavirus 2 (SARS-CoV-2) epidemic and associated events around the world: How 21st century GIS technologies are supporting the global fight against outbreaks and epidemics," International Journal of Health Geographics, vol. 19, no. 1, pp. 1-12, 2020.

[49] IoT business news, "Visionstate ships first IoT buttons for rapid response to cleaning alerts," 2020. [Online]. Available: https://iotbusinessnews.com/2020/03/23/61987-visionstate-ships-first-iot-buttons-for-rapid-responseto-cleaning-alerts/.

[50] Globenewswire, "Visionstate ships first iot buttons for rapid response to cleaning alerts," 2020. [Online]. Available: https://www.globenewswire.com/news-release/2020/03/23/2004645/0/en/Visionstate-Ships-First-IoTButtons-for-Rapid-Response-to-Cleaning-Alerts.html.

[51] IoT business news, "Aranet releases a large-scale wireless body temperature monitoring solution for hospitals battling COVID-19,” 2020. [Online]. Available: https://iotbusinessnews.com/2020/04/10/20704-aranetreleases-a-large-scale-wireless-body-temperature-monitoring-solution-for-hospitals-battling-covid-19/.

[52] Electronic measuring instruments, "Wireless body temperature monitoring solution for hospitals battling COVID-19 Aranet TDSPTK01,” 2020. [Online]. Available: https://www.emi-lda.com/en/wirelesstemperature-data-loggers/432-wireless-body-temperature-monitoring-solution-for-hospitals-battling-covid-19aranet-tdsptk01.html.

[53] Aranet, "Large-scale wireless body temperature monitoring solution for hospitals battling COVID-19," 2020. [Online]. Available: https://aranet.com/large-scale-wireless-body-temperature-monitoring-solution-for-hospitalsbattling-covid-19/.

[54] D. Koh, "Cassia's gateways allow up to 40 Bluetooth low energy devices to be paired and connected simultaneously while providing the long-range connectivity needed to cover multiple rooms in the SPHCC. Mobi health news," 2020. [Online]. Available: https://www.mobihealthnews.com/news/asia-pacific/sphccemploys-iot-tech-and-wearable-sensors-monitor covid-19-patients..

[55] C. Russey, "SPHCC Partners with cassia and VivaLNK to use wearable tech for monitoring COVID-19 patients," 2020. [Online]. Available: https://www.wearable-technologies.com/2020/04/sphcc-partners-with-cassia-andvivalnk-to-use-wearable-tech-for-monitoring-covid-19-patients/.

[56] Bio spectrum Asia, "Singapore creates world's first IOT-enabled Tele-Ventilator," 2020. [Online]. Available: https://www.biospectrumasia.com/news/27/15812/singapore-creates-worlds-first-iot-enabled-tele-ventilator.html.

[57] Asia pacific biotech news, 2020, Innovation in healthcare: IOT-enabled Tele-Ventilators to fight against the COVID-19 Pandemic., https://www.asiabiotech.com/new-crunch/2020-04-23-01.html\#gsc.tab=0. 
[58] M. A. Ahmed, "An intelligent healthcare service to monitor vital signs in daily life: A case study on health-IoT," International Journal of Engineering Research and Application, vol. 7, no. 3, pp. 43-55, 2017.

[59] J. Fadia, "Smart city strategies to fight COVID-19 in dense urban areas. IoT evolution," 2020. [Online]. Available: https://www.iotevolutionworld.com/iot/articles/445217-smart-city-strategies-fight-covid-19-dense-urban.htm.

[60] T. Guarda, M. Leon, M. F. Augusto, L. Haz, M. De la Cruz et al., "Internet of things challenges," in 12th Iberian Conf. on Information Systems and Technologies, Lisbon, Portugal, pp. 1-4, 2017.

[61] H. Rahman and R. Rahmani, "Enabling distributed intelligence assisted future Internet of Things controller (FITC)," Applied Computing and Informatics, vol. 14, no. 1, pp. 73-87, 2017.

[62] H. N. Saha, N. Saha, R. Ghosh and S. Roychoudhury, "Recent trends in implementation of Internet of Things: A review," in 2016 IEEE 7th Annual Information Technology, Electronics and Mobile Communication Conf. (IEMCON), Vancouver, BC, Canada, pp. 1-6, 2016.

[63] K. B. Ooi, V. H. Lee, G. W. H. Tan, T. S. Hew and J. J. Hew, "Cloud computing in manufacturing: The next industrial revolution in Malaysia," Expert Systems with Applications, vol. 93, no. 3, pp. 376-394, 2018.

[64] S. Zeadally, J. T. Isaac and Z. Baig, "Security attacks and solutions in electronic health (e-health) systems," Journal of Medical Systems, vol. 40, no. 12, pp. 263, 2016.

[65] P. A. Williams and V. McCauley, "Always connected: The security challenges of the healthcare Internet of Things," in 3rd World Forum on Internet of Things, Reston, VA, USA, pp. 30-35, 2016.

[66] A. K. Das, S. Zeadally and D. He, "Taxonomy and analysis of security protocols for Internet of Things," Future Generation Computer Systems, vol. 89, no. 12, pp. 110-125, 2018.

[67] S. Sonune, D. Kalbande, A. Yeole and S. Oak, "Issues in IoT healthcare platforms: a critical study and review," in Int. Conf. on Intelligent Computing and Control, Coimbatore, India, pp. 1-5, 2017.

[68] Hipaa, "Health information privacy," 2020. [Online]. Available: www.hhs.gov/hipaa/index.html.

[69] C. De Grood, A. Raissi, Y. Kwon and M. J. Santana, "Adoption of e-health technology by physicians: A scoping review," Journal of Multidisciplinary Healthcare, vol. 9, no. 1, pp. 334-335, 2016.

[70] D. Tse, C. K. Chow, T. P. Ly, C. Y. Tong and K. W. Tam, "The challenges of big data governance in healthcare," in 17th IEEE Int. Conf. on Trust, Security and Privacy in Computing and Communications/12th IEEE Int. Conf. on Big Data Science and Engineering, New York, USA, pp. 1632-1636, 2018.

[71] U. M. Badarudin, W. I. S. W. Din, Y. A. Prasetyo, Z. Musa and S. Kasim, "Internet of Things: An implementation and its challenges in malaysia," International Journal on Advanced Science, Engineering and Information Technology, vol. 6, no. 1, pp. 2641-2647, 2018.

[72] I. Lee and K. Lee, "The Internet of Things (IoT): Applications, investments, and challenges for enterprises," Business Horizons, vol. 58, no. 4, pp. 431-440, 2015.

[73] Y. I. N. Yuehong, Y. Zeng, X. Chen and Y. Fan, "The Internet of Things in healthcare: An overview," Journal of Industrial Information Integration, vol. 1, no. 1, pp. 3-13, 2016.

[74] T. L. Inn, "Smart city technologies take on COVID-19. Penang institute issue," 2020. [Online]. Available: https:// penanginstitute.org/publications/issues/smart-city-technologies-take-on-covid-19/.

[75] T. P. Hanna, G. A. Evans and C. M. Booth, "Cancer, COVID-19 and the precautionary principle: Prioritizing treatment during a global pandemic," Nature Reviews Clinical Oncology, vol. 17, no. 5, pp. 268-270, 2020.

[76] D. Roy, S. Tripathy, S. K. Kar, N. Sharma, S. K. Verma et al., "Study of knowledge, attitude, anxiety \& perceived mental healthcare need in indian population during COVID-19 pandemic," Asian Journal of Psychiatry, vol. 51, no. 6, pp. 1-7, 2020.

[77] T. Y. Wong and F. Bandello, "Academic ophthalmology during and after the COVID-19 pandemic," Ophthalmology, vol. 127, no. 8, pp. e51-e52, 2020.

[78] M. Choudhary, "How IoT can help fight COVID-19 battle," 2020. [Online]. Available: https://www. geospatialworld.net/blogs/how-iot-can-help-fight-covid-19-battle/. 